\title{
Development of an Energy Management System for Hybrid Power Generation (HPG) using IoT
}

\author{
S Sivakumar ${ }^{1}$, Dr S Baskar ${ }^{2}$ \\ ${ }^{1}$ Research Scholar, Department of EEE, Vel Tech Rangarajan Dr.Sagunthala R\&D Institute of Science and \\ Technology, Avadi, Chennai, Tamil Nadu-600062, India. \\ ${ }^{2}$ Professor, Department of EEE, Vel Tech Rangarajan Dr.Sagunthala R\&D Institute of Science and Technology, \\ Avadi, Chennai, Tamil Nadu-600062, India
}

\begin{abstract}
A intelligent networks are a disseminated framework comprising of a lot of intelligent home that uses the intelligent abode booking strategy for empowering clients toward naturally plan its vitality load focusing on different purposes, for example, power charge decrease. Using LABVIEW and embedded technology, electricity bill of both renewable energy and utility energy are managed, monitored and controlled simultaneously. Based on the time scheduling, renewable energy is utilized by the customers at their corresponding time slots. And on other timings they utilize normal electricity which is distributed by the government. Based on the consumption of electricity, bill is generated using LABVIEW. With the improvement of expectation for everyday comforts of the individuals, unrivaled electrical results of PC, closed circuit TV, water distributor, cooling and other show up in the understudy lodgings, it is hard to control electrical amounts and charge; it additionally creates a great deal of inquiry concerning safe, economy, the executives and other. What's more, a serious cross entropy enhancement procedure is proposed to figure such an evaluating plan which is additionally coordinated with smart home planning. The reproduction results show the decrease of both the network wide power bill and individual power charge contrasted with the cutting edge smart home planning strategy.
\end{abstract}

Key words: Power Consumption, Internet on Things, Hybrid Power Generation and LABVIEW.

\section{INTRODUCTION}

In India the interest of power per head is more than age of power. Besides till December 2011, more than 300 million Indian residents had no admittance to power. With the developing populace the interest is additionally expanding. Nonetheless, age of power isn't expanding at the pace [1]. In the image it is giving a decent indication as lack of power in top is decreasing step by step [2].

In any event, during top hours (at night) the interest is at its pinnacle, so to fulfill the need of significant divisions/city, supply must be shortened in less significant territories and towns [3.] Even though new power generating units are being introduced, the power demand cannot be satisfied till date [4]. However, the power demand can be restricted to a certain limit during various time periods in a day.

The smart network includes the programmed control of family unit exercises to all the homes. This develops dependability, qualities as well as effectiveness of the power supply as well as impacts the utilization of power vitality by way of intelligent abode booking as well as sustainable power source combination. Sustainable power source assets are usually accessible at network level which is commonly modest $[15$

The people group level sustainable power source could be wind turbines else huge PV board that has been open for every client in the network [6]. Clients can be provided straightforwardly with network level sustainable power source that mitigate the weight of power plant as well as power broadcast organizations [7]. Notwithstanding, clients in a network need to contend with one another for the restricted assets of sustainable power source [8].

A decentralized methodology is generally embraced to actualize smart home planning. The power bill of the network is processed dependent on the all out vitality load shared by the clients [9]. Along these lines a typical thought of decentralizing intelligent abode booking methods should constantly plan the vitality use of every client to limit the power bill [10]. This thought neglects to address the opposition on network level sustainable power source [11]. Note the utility vitality and sustainable power source as a rule converge at the substation of the network [12].

To handle this test our proposed valuing plan fills in as follows. At each time allotment every client gets a markdown factor allocated by the network level approach creator representing the power charge decrease because of utilizing sustainable power source [13]. Furthermore a serious cross entropy streamlining procedure is projected toward figure much a valuing plan for incorporating through intelligent abode planning [14].

\section{POWER SUPPLY UNIT}

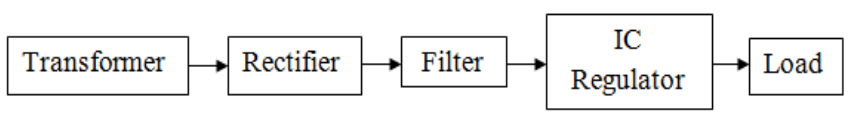

Figure 1: Block Diagram for Power Supply Unit 
Power Supply: The AC voltages, commonly $220 \mathrm{~V}$ rms, are related through transformers, that path such as the air condition voltage downward toward the level of the perfect dc yields. Diode rectifiers just then provide complete-wave redressed voltages which are on initially filtered through a straightforward capacitor filter for delivering DC voltages. These successive dc voltages like a regulation have several waves else air condition voltage varieties. A controller circuits eliminates the wave, likewise persists like by dc value apart from if the data dc voltage fluctuates. The square outline of the power supply is appeared in figure 1 .

Transformer: The prospective transformers would track downwards the power supply voltage $(0-230 \mathrm{~V})$ to $(0-9 \mathrm{~V}$ and 15-0-15) levels. In the event so as to the supplementary have lesser turn within the curl, then the vital, the elective loop's voltage would diminish as well as the existing otherwise AMP would increment else diminished rely on the wire's measure. It's known as STEP-DOWN transformers. At that point the auxiliary of the latent transformers are associated with the rectifiers.

Bridge Rectifier: Once 4 diodes have been associated like appeared within diagram, the circuits are named to bridge rectifiers. The contributions for the circuits are executed to the askew inverse corner of the organization, as well as the yields are being used as of the staying two corners.

Filter: When Capacitors are included corresponding by the load resistor of Rectifiers toward shape a basic Filter Circuits, the yield of the Rectifiers are changed in a steadier DC Voltages. From the start, the capacitors have been charging to the pinnacle estimation of the redressed Waveforms. Past the pinnacle, the capacitors are released during the load resistors up to the moment where the redressed voltages surpass the capacitor's voltages. At that point the capacitors have been charging once more as well as the cycle rehashes on its own.

IC Voltage Regulators: Voltage regulator involves a group of broadly utilized IC. Controller Integrated Circuit unit have the hardware towards reference sources, comparator intensifier, control gadget, as well as overload's insurance every into a solitary Integrated Circuits. ICs unit give guideline of any rigid positive voltages. The regulator is selected towards activity by load flows as of numerous $\mathrm{mA}$ toward several amperes, relating toward power evaluation as of $\mathrm{mW}$ toward many watt.

Load: The load might be engine otherwise some extra loads. It has been switched ON as well as OFF during hand-off. The transfer ON also OFF has been constrained with the couple of exchanging semiconductors (BC 547). The transfers are associated into the Q2 semiconductor gatherer terminals. A Relay has only electromagnetic exchanging gadget that comprises of 3 pins which are Common, Normally close (NC) also normally open (NO).

\section{SMART INTELLIGENT SYSTEM}

The smart network includes the programmed control of family unit exercises for each home. In the network, every client plans the vitality consumption of the home machines utilizing the smart home regulator. In the network, every client plans the vitality consumption of the home machines utilizing the smart home regulator. Recreations are led to show the presentation of the proposed algorithm. The house hold unit is powered through a hybrid power supply. Hybrid power supply in the sense consists of renewable energy and utility energy. House hold units will be consuming renewable energy based on time scheduling. Think a small society having only 2 consumers. For the first two hours the consumer 1 will get supply from renewable energy. And for the next two hours consumer 2 will get supply from renewable energy. When the renewable energy is shifted from consumer 1 to consumer 2, the consumer 1 will get the supply from utility energy which is distributed by the government. At the same time when the renewable energy is shifted from consumer 2 to consumer 1 , the consumer 2 will get the supply from utility energy which is distributed by the government. The time scheduling is programmed using LABVIEW. In our proposed system LABVIEW is used for EB bill monitoring and generating purpose for each consumer and also it is used for controlling load sections. The consumption of renewable energy and utility energy is received via SMS with the help of GSM or IoT module.

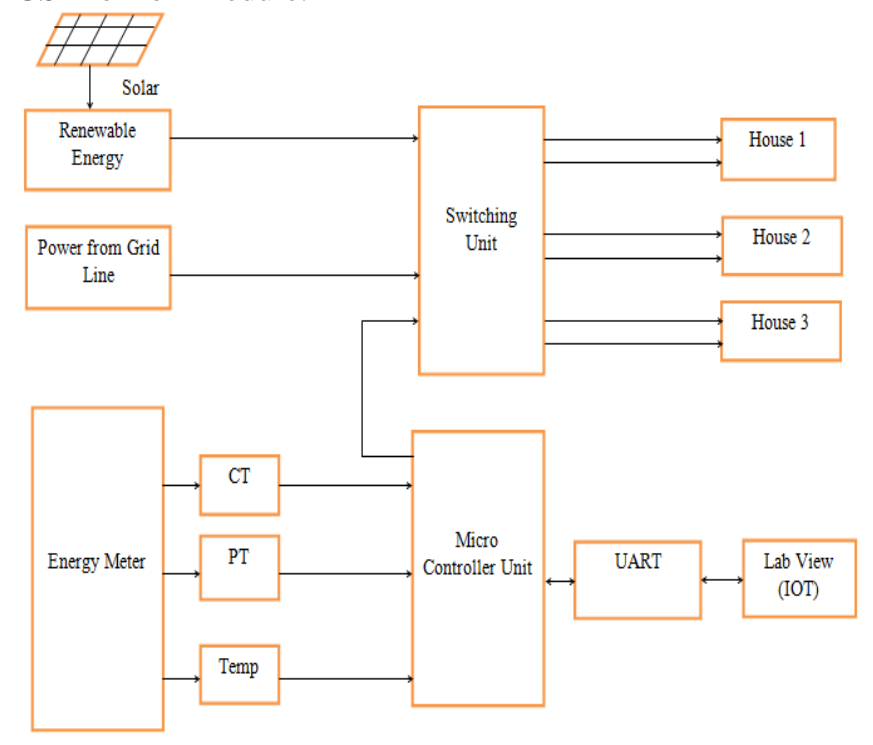

Figure 2: Smart Intelligent System

Power Supply: A gadgets otherwise frameworks which provides electric else diverse kinds of energy for yielding loads else get-together of loads are named as a power supply unit or PSU. Power supplies for electronic gadgets can be comprehensively partitioned into straight and exchanging power supplies. The direct supply is a generally basic plan that turns out to be progressively massive and substantial for high current gadgets; voltage guideline in a straight supply can bring about low productivity. An exchanged mode supply of a similar rating as a direct supply will be littler, is normally more productive, however will be more perplexing. 
PIC 16f877A: Various microcontroller offers different kinds of recollection. EEPROM, EPROM, FLASH also many more has been a part of the recollection where FLASH has been the the majority since delay produced. Innovations are exploited into pic16F877 has been smudge innovations, hence data has been apprehended in any event, once the power has been turned off. Easy coding as well as Eradicating has been diverse highlight of PIC 16F877A.

Relay Circuit: Gate pulses are provided to the relay and alarm through the driver circuit. This is implemented by providing one driver for each i.e. one for alarm and one for the relay circuit. The gate pulses are fed to the gate terminal of the alarm and relay circuit. The gate pulse is a pulse that triggers a gate circuit so that it allows passage of current.

Load: If an electric circuit has an all around characterized yield terminal, the circuit associated with this terminal has been the load. Load influence the exhibition of circuit that yields voltage else flow, such as, sensor, voltage source, as well as intensifiers. Main power outlets provide a straightforward models: it supplies power on stable voltages, through electric apparatus linked through the power circuits the entire things considered formation of the load. In this stage, as soon as a high-power apparatus turns on, it significantly decreases the load impedance.

Level Converter: Its the ability of changing over four pins at the higher sides toward four pins at the lower sides of the 2 data sources also 2 yields accommodated all sides. The boards should be charged as of the 2 voltage source (high voltages as well as low voltages) such as our framework has been utilized. High voltages ( $5 \mathrm{~V}$ for instance) toward the 'HV' pins, low voltages ( $3.3 \mathrm{~V}$ for instance) toward ' $\mathrm{LV}$ ', also ground as of the framework towards the 'GND' pins.

GSM Module: The SIM300 has been a complete Quad-band GSM/GPRS collection into a SMT modules where its been implemented into the customer application. together with an industry standard interfaces, the SIM300 communicates GSM/GPRS 850/900/1800/1900MHz implementation over voices, SMS, Data, as well as Fax into a small structure factor also through lower power consumption. By a small arrangement of $24 \mathrm{~mm} \times 24 \mathrm{~mm} \times 3 \mathrm{~mm}$, SIM300 could fix practically the entire gap provisions into our M2M applications, predominantly towards slim as well as reduced significance of plan.

IoT Module: This has a tiny electric gadgets implemented into item, devices as well as things which interfaces through distant organizations furthermore transmits as well as recieves data. Another key differentiator of IoT modules is that they give consistently on availability.

\section{RESULTS AND DISCUSSION}

The simulated results with experimental demonstration are shown in this section. Figure 3 shows the simulations results of Grid with IoT technology used. Similarly Figure 4 and Figure 5 show the simulations results of Solar and Wind with IoT technology used.

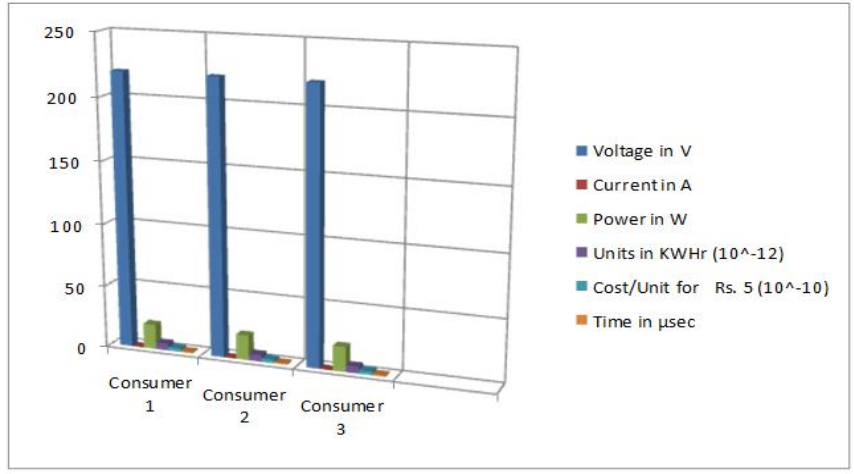

Figure 3: Simulations Results for Grid with IoT

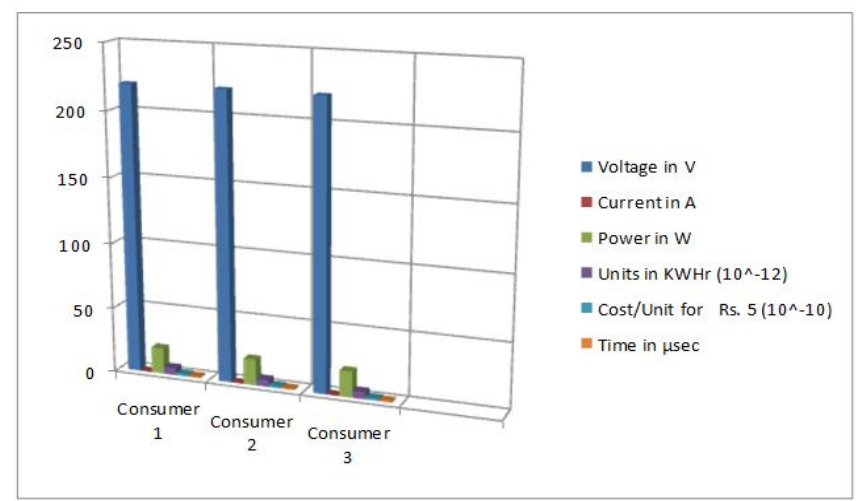

Figure 4: Simulations Results for Solar with IoT

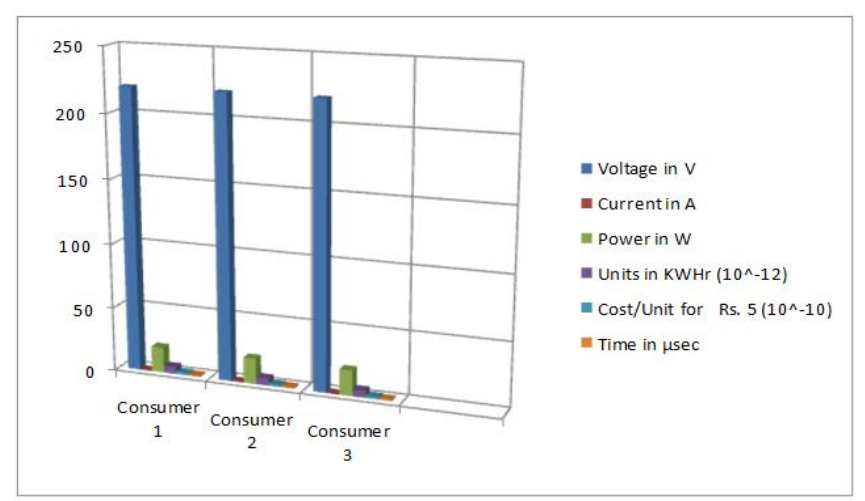

Figure 5: Simulations Results for Wind with IoT

Table 1 describes the simulations results of Grid with IoT technology used. Similarly Table 2 and Table 3 describe the simulations results of Solar and Wind with IoT technology used.

Table 1: Simulations Results for Grid with IoT

\begin{tabular}{|c|c|c|c|c|c|c|}
\hline & \multicolumn{6}{|c|}{ Solar } \\
\cline { 2 - 7 } & $\begin{array}{c}\text { Voltage } \\
\text { in V }\end{array}$ & $\begin{array}{c}\text { Current } \\
\text { in A }\end{array}$ & $\begin{array}{c}\text { Power } \\
\text { in W }\end{array}$ & $\begin{array}{c}\text { Units in } \\
\text { KW/Hr }\end{array}$ & $\begin{array}{c}\text { Cost/Unit } \\
\text { for Rs. 5 }\end{array}$ & $\begin{array}{c}\text { Time } \\
\text { in } \\
\mu \text { sec }\end{array}$ \\
\hline Consumer 1 & 220 & 0.09 & 20 & $\begin{array}{c}5.5 \times 10^{\wedge} \\
12\end{array}$ & $\begin{array}{c}2.77 \times 10^{\wedge} \\
10\end{array}$ & 1 \\
\hline Consumer 2 & 220 & 0.09 & 20 & $\begin{array}{c}5.5 \times 10^{\wedge} \\
12\end{array}$ & $\begin{array}{c}2.77 \times 10^{\wedge} \\
10\end{array}$ & 1 \\
\hline Consumer 3 & 220 & 0.09 & 20 & $\begin{array}{c}5.5 \times 10^{\wedge} \\
12\end{array}$ & $\begin{array}{c}2.77 \times 10^{\wedge} \\
10\end{array}$ & 1 \\
\hline
\end{tabular}


S Sivakumar et al., International Journal of Emerging Trends in Engineering Research, 8(9), September 2020, 6226 - 6230

Table 2: Simulations Results for Solar with IoT

\begin{tabular}{|l|c|c|c|c|c|c|}
\hline & \multicolumn{6}{|c|}{ Solar } \\
\cline { 2 - 7 } & $\begin{array}{c}\text { Voltage } \\
\text { in V }\end{array}$ & $\begin{array}{c}\text { Current } \\
\text { in A }\end{array}$ & $\begin{array}{c}\text { Power } \\
\text { in W }\end{array}$ & $\begin{array}{c}\text { Units in } \\
\text { KW/Hr }\end{array}$ & $\begin{array}{c}\text { Cost/Unit } \\
\text { for Rs. 5 }\end{array}$ & $\begin{array}{c}\text { Time } \\
\text { in } \\
\text { usec }\end{array}$ \\
\hline Consumer 1 & 220 & 0.09 & 20 & $\begin{array}{c}5.5 \times 10 \\
12\end{array}$ & $\begin{array}{c}1.65 \times 10 \\
10\end{array}$ & 1 \\
\hline Consumer 2 & 220 & 0.09 & 20 & $\begin{array}{c}5.5 \times 10 \\
12\end{array}$ & $\begin{array}{c}1.65 \times 10 \\
10\end{array}$ & 1 \\
\hline Consumer 3 & 220 & 0.09 & 20 & $\begin{array}{c}5.5 \times 10 \\
12\end{array}$ & $\begin{array}{c}1.65 \times 10 \\
10\end{array}$ & 1 \\
\hline
\end{tabular}

Table 3: Simulations Results for Wind with IoT

\begin{tabular}{|c|c|c|c|c|c|c|}
\hline & \multicolumn{6}{|c|}{ Solar } \\
\cline { 2 - 7 } & $\begin{array}{c}\text { Voltage } \\
\text { in V }\end{array}$ & $\begin{array}{c}\text { Current } \\
\text { in A }\end{array}$ & $\begin{array}{c}\text { Power } \\
\text { in W }\end{array}$ & $\begin{array}{c}\text { Units in } \\
\text { KW/Hr }\end{array}$ & $\begin{array}{c}\text { Cost/Unit } \\
\text { for Rs. 5 }\end{array}$ & $\begin{array}{c}\text { Time } \\
\text { in } \\
\mu \text { sec }\end{array}$ \\
\hline Consumer 1 & 220 & 0.09 & 20 & $\begin{array}{c}5.5 \times 10^{\wedge} \\
12\end{array}$ & $\begin{array}{c}1.65 \times 10^{\wedge} \\
10\end{array}$ & 1 \\
\hline Consumer 2 & 220 & 0.09 & 20 & $\begin{array}{c}5.5 \times 10^{\wedge} \\
12\end{array}$ & $\begin{array}{c}1.65 \times 10^{\wedge} \\
10\end{array}$ & 1 \\
\hline Consumer 3 & 220 & 0.09 & 20 & $\begin{array}{c}5.5 \times 10^{\prime} \\
12\end{array}$ & $\begin{array}{c}1.65 \times 10 \\
10\end{array}$ & 1 \\
\hline
\end{tabular}

Figure 6 shows the simulations results of Grid without IoT technology used. Similarly Figure 7 and Figure 8 show the simulations results of Solar and Wind without IoT technology used.

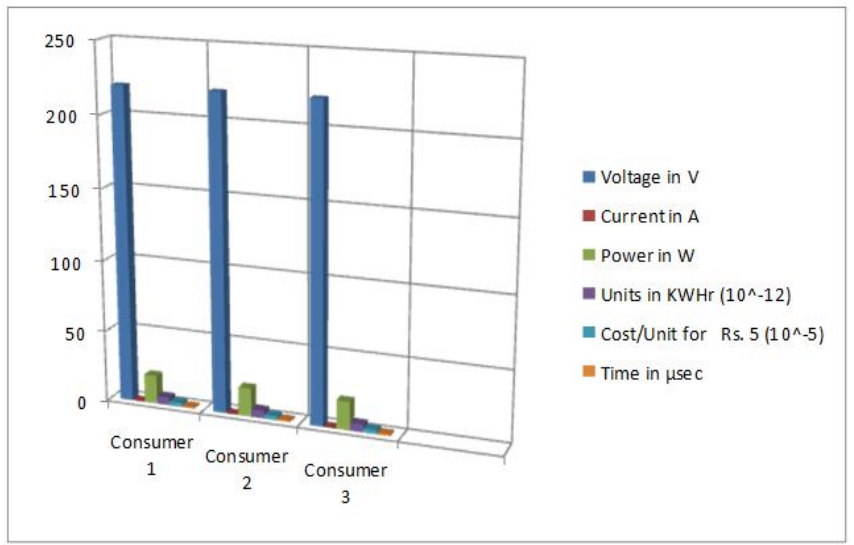

Figure 6: Simulations Results for Grid without IoT

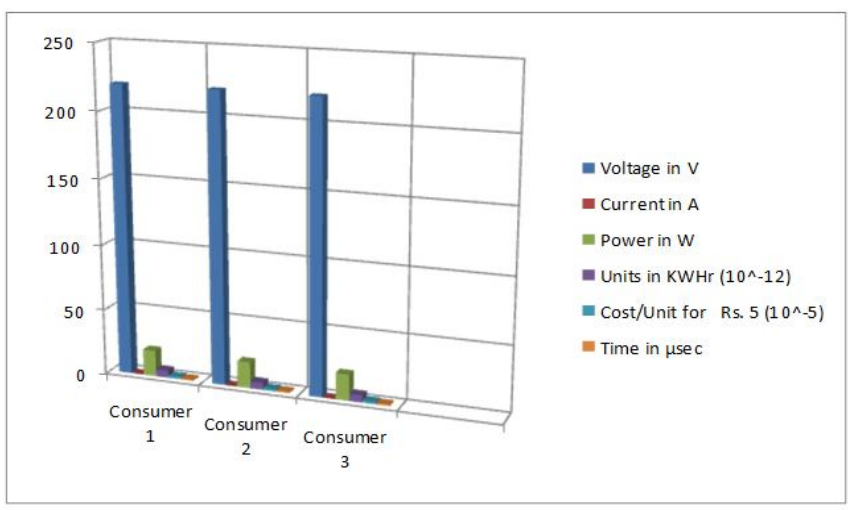

Figure 7: Simulations Results for Solar without IoT

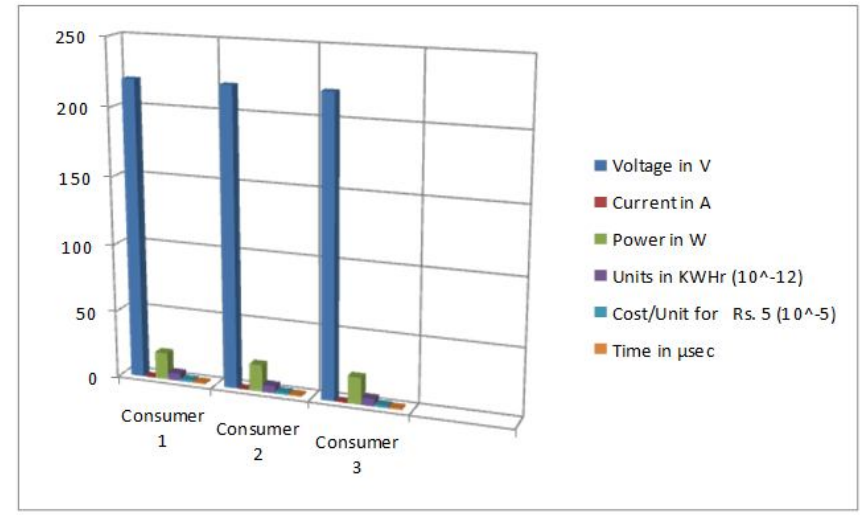

Figure 8: Simulations Results for Wind without IoT

Table 4 describes the simulations results of Grid without IoT technology used. Similarly Table 5 and Table 6 describe the simulations results of Solar and Wind without IoT technology used.

Table.4 Simulations Results for Grid without IoT

\begin{tabular}{|l|c|c|c|c|c|c|}
\hline & \multicolumn{6}{|c|}{ Solar } \\
\cline { 2 - 7 } & $\begin{array}{c}\text { Voltage } \\
\text { in V }\end{array}$ & $\begin{array}{c}\text { Current } \\
\text { in A }\end{array}$ & $\begin{array}{c}\text { Power } \\
\text { in W }\end{array}$ & $\begin{array}{c}\text { Units in } \\
\text { KW/Hr }\end{array}$ & $\begin{array}{c}\text { Cost/Unit } \\
\text { for Rs. 5 }\end{array}$ & $\begin{array}{c}\text { Time } \\
\text { in } \\
\text { usec }\end{array}$ \\
\hline Consumer 1 & 220 & 0.09 & 20 & $\begin{array}{c}5.5 \times 10 \\
12\end{array}$ & $\begin{array}{c}2.77 \times 10 \\
5\end{array}$ & 1 \\
\hline Consumer 2 & 220 & 0.09 & 20 & $\begin{array}{c}5.5 \times 10 \\
12\end{array}$ & $\begin{array}{c}2.77 \times 10 \\
5\end{array}$ & 1 \\
\hline Consumer 3 & 220 & 0.09 & 20 & $\begin{array}{c}5.5 \times 10 \\
12\end{array}$ & $\begin{array}{c}2.77 \times 10 \\
5\end{array}$ & 1 \\
\hline
\end{tabular}

Table.5 Simulations Results for Solar without IoT

\begin{tabular}{|c|c|c|c|c|c|c|}
\hline & \multicolumn{6}{|c|}{ Solar } \\
\cline { 2 - 7 } & $\begin{array}{c}\text { Voltage } \\
\text { in V }\end{array}$ & $\begin{array}{c}\text { Current } \\
\text { in A }\end{array}$ & $\begin{array}{c}\text { Power } \\
\text { in W }\end{array}$ & $\begin{array}{c}\text { Units in } \\
\text { KW/Hr }\end{array}$ & $\begin{array}{c}\text { Cost/Unit } \\
\text { for Rs. 5 }\end{array}$ & $\begin{array}{c}\text { Time } \\
\text { in } \\
\text { usec }\end{array}$ \\
\hline Consumer 1 & 220 & 0.09 & 20 & $\begin{array}{c}5.5 \times 10 \\
12\end{array}$ & $\begin{array}{c}1.65 \times 10 \\
5\end{array}$ & 1 \\
\hline Consumer 2 & 220 & 0.09 & 20 & $\begin{array}{c}5.5 \times 10 \\
12\end{array}$ & $\begin{array}{c}1.65 \times 10 \\
5\end{array}$ & 1 \\
\hline Consumer 3 & 220 & 0.09 & 20 & $\begin{array}{c}5.5 \times 10 \\
12\end{array}$ & $\begin{array}{c}1.65 \times 10 \\
5\end{array}$ & 1 \\
\hline
\end{tabular}

Table.6 Simulations Results for Wind without IoT

\begin{tabular}{|l|c|c|c|c|c|c|}
\hline & \multicolumn{6}{|c|}{ Solar } \\
\cline { 2 - 7 } & $\begin{array}{c}\text { Voltage } \\
\text { in V }\end{array}$ & $\begin{array}{c}\text { Current } \\
\text { in A }\end{array}$ & $\begin{array}{c}\text { Power } \\
\text { in W }\end{array}$ & $\begin{array}{c}\text { Units in } \\
\text { KW/Hr }\end{array}$ & $\begin{array}{c}\text { Cost/Unit } \\
\text { for Rs. 5 }\end{array}$ & $\begin{array}{c}\text { Time } \\
\text { in } \\
\mu \text { sec }\end{array}$ \\
\hline Consumer 1 & 220 & 0.09 & 20 & $\begin{array}{c}5.5 \times 10^{\wedge} \\
12\end{array}$ & $\begin{array}{c}1.65 \times 10^{\wedge} \\
5\end{array}$ & 1 \\
\hline Consumer 2 & 220 & 0.09 & 20 & $\begin{array}{c}5.5 \times 10^{\wedge} \\
12\end{array}$ & $\begin{array}{c}1.65 \times 10^{\wedge} \\
5\end{array}$ & 1 \\
\hline Consumer 3 & 220 & 0.09 & 20 & $\begin{array}{c}5.5 \times 10^{\wedge} \\
12\end{array}$ & $\begin{array}{c}1.65 \times 10 \\
5\end{array}$ & 1 \\
\hline
\end{tabular}

\section{CONCLUSION}

In this research work, a novel idea is proposed to control the consumption of energy during peak hours by using load shedding techniques. By implementing this research work, frequent power shutdowns can be avoided. GSM/IoT module helps in updating the power supply consumed everyday dynamically. The value of reference power can be updated regularly everyday with respect to the real time power 
generation. The generated power can be distributed equally to all the end users during peak hours. During the peak hours, there is a low voltage due to power demand. When this low voltage is supplied to the electrical appliances, it results in reduction in efficiency and appliance degradation. This condition can be avoided by implementing this research work. Cost per unit is updated by using the GSM/IoT module. Electricity bill can be automatically calculated and the bill can be sent to the mobile and the utility using the GSM/IoT module.

\section{REFERENCES}

1. L. Liu, X. Yang, H. Huang, and S. Hu, "Smart home scheduling for cost reduction and its implementation on FPGA," Journal of Circuit, System and Computers, vol. 24, no. 4, pp. 1-15, 2015.

2. L. Zhang, W. Wu, and D. Wang, "Time dependent pricing in wireless data networks: Flat-rate vs. usage-based schemes," in Proceedings of IEEE INFOCOM, April 2014, pp. 700-708.

3. N. Tran, C. S. Hong, Z. Han, and S. Lee, "Optimal pricing effect on equilibrium behaviors of delay-sensitive users in cognitive radio networks," IEEE Journal on Selected Areas in Communications, vol. 31, no. 11, pp. 2566-2579, November 2013.

4. J. Han, C.-S. Choi, and I. Lee, "More efficient home energy management system based on zigbee communication and infrared remote controls," IEEE Trans. on Consumer Electron., vol. 51, no. 1, pp. 85-89, Feb. 2011.

5. A.-H. Mohsenian-Rad, V. Wong, J. Jatskevich, R. Schober, and A. Leon-Garcia, "Autonomous demand-side management based on game-theoretic energy consumption scheduling for the future smart grid," IEEE Transactions on Smart Grid, vol. 1, no. 3, pp. 320-331, Dec 2010.

6. D. Westermann and M. Kratz, "A real-time development platform for the next generation of power system control functions," IEEE Trans. Ind. Electron., vol. 57, no. 4, pp. 1159-1166, Apr. 2010.

7. J. Taneja, D. Culler, and P. Dutta, "Towards cooperative grids: Sensor/ actuator networks for renewables integration," in Proc. 1st IEEE Int. Conf. Smart Grid Comm., 2010, pp. 531-536.

8. H. Li, M. Steurer, K. L. Shi, S. Woodruff, and D. Zhang, "Development of a unified design, test, and research platform for wind energy systems based on hardware-in-the-loop real-time simulation," IEEE Trans. Ind. Electron., vol. 53, no. 4, pp. 1144-1151, Jun. 2006.

9. W.Kellogg, M. Nehrir, G.Venkataramanan, and V.Gerez, "Generation unit sizing and cost analysis for stand-alone wind, photovoltaic, and hybrid wind/PV systems," IEEE Trans. Energy Convers., vol. 13, no.1, pp. 70-75, Mar. 1998.

10. W. Kellogg, M. Nehrir, G. Venkataramanan, and V. Gerez, "Optimal unit sizing for a hybrid wind/photovoltaic generating system," Elect.Power Syst. Res., vol. 39, no. 1, pp. 35-38, Oct. 1996.

11. G Ramprabu, S Sivakami, M Kanmani, "Performance Analysis of IoT based Smart Agriculture System", International Journal of Engineering and Advanced Technology, Volume 8, Issue 4, April 2019, pp.1342-1344.

12. N Murali Krishnan, B Muthuvel, Chaladi Maniteja and G Ramprabu, "Performance Evaluation of Hybrid Controller involved in 3 Phase to 3 Phase Power Conversion using Matrix Converter", International Journal of Electrical Engineering \& Technology, Volume 11, Issue 1, January-February 2020, pp.26-42.

13. K. Ruth Ramya, B. Manjula Josephine, K. Durga Praveen, M. Bala Maruthi, Ch.Sai Kumar, "An Efficient and Secured Biometric Authentication for IoT", International Journal of Emerging Trends in Engineering Research, Volume 7, Issue 11, November 2019, pp.604-609.

14. Venkata Sai Kumar, Gunti Spandan, B Chakri, Dinesh Babu, "Fingerprint Authentication and Mobile App Based Monitoring of Vehicles Using IOT", International Journal of Emerging Trends in Engineering Research, Volume 8, Issue 5, May 2020, pp.1785-1789. 